\title{
Trapping efficacy to control the wild Boar (Sus scrofa) population in Islamabad, Pakistan
}

\author{
Irfan Ashraf ${ }^{*}$, Ishtiaq Ahmad ${ }^{2}$, Syed Asad Hussain Bukhari ${ }^{3}$ and \\ Ambreen Maqsood ${ }^{2}$ \\ 1. Department of Forestry, Range \& Wildlife Management, The Islamia University of Bahawalpur, Pakistan \\ 2. University College of Agriculture, the Islamia University of Bahawalpur, Pakistan \\ 3. Department of Agronomy, Faculty of Agricultural Sciences and technology, Bahauddin Zakariya University, \\ Multan, Pakistan \\ *Corresponding author's email: irfanmanj@gmail.com
}

Citation

Irfan Ashraf, Ishtiaq Ahmad, Syed Asad Hussain Bukhari and Ambreen Maqsood. Trapping efficacy to control the wild Boar (Sus scrofa) population in Islamabad, Pakistan. Pure and Applied Biology. Vol. 5, Issue 1, 2016, pp177182. http://dx.doi.org/10.19045/bspab.2016.50023

\begin{tabular}{llll}
\hline \hline Received: 07/01/2016 & Revised: 25/01/2016 & Accepted: 29/01/2016 & Online First: 01/02/2016 \\
\hline \hline
\end{tabular}

\section{Abstract}

Wild Boar (Sus scrofa), an important artiodactyl mammal of family Suidae, is reported as an agricultural pest. It causes damage to sugarcane, oil seeds and several grain crops. Present studies were conducted towards efficient management of this animal through various trapping techniques, as chemical and shooting was not recommended in the study site due to environmental, social and security issues in Islamabad. There were three different types of traps (double spike snare traps, loop traps and panel traps) were used to control the population of wild boar. During two years of trapping study, a total of 529 wild boars were trapped from seven different study sites located in the vicinity of Islamabad. Out of these, 277 were trapped during the first year and 252 in the year 2. The maximum ( 84 animals) heads were captured Faisal Mosque (46 in year 1 and 35 in year 2) followed by a catch of 81 at F-9 Park (36 in year 1 and 45 in year 2). The comparison of trapping devises was made from the results it is indicated that, the most efficient was panel trap, through which a total of 277 animals were captured in two years followed by 111 and 107 from loop traps and snare traps, respectively.

Key words: Wild Boar; Crops damage; Traps; Mechanical control

\section{Introduction}

Wild boar, an important artiodactyl mammal, belongs to family Suidae and indigenous to Western Europe and Northern Africa, ranging eastwards across the Mediterranean basin through India and South-East Asia to Japan, Sri Lanka, Java, Taiwan, Korea and Malaya [1]. There are eight species of pigs distributed throughout Europe, Asia and Africa. Out of these, only the wild boar (Sus scrofa) has twenty one sub-species. The sub-species present in subcontinent, Pakistan and India is Sus scrofa cristatus [2]. In Pakistan, wild boars are found in the upland areas up to about $1000 \mathrm{~m}$ elevation and at lower elevations throughout Punjab, parts of Khyber Pakhtukhwan, and in Sindh to the mouth of the Indus River [3]. Threats of their damage to agriculture are increasing due to 
their eating habits causing more damage to cultivated crops in the agriculture biomes. Their heavy numbers are extremely helpful in disseminating parasites and diseases like foot and mouth disease, rabies, etc. and therefore pose a serious threat to local livestock and other pets [4].

The increases in wild boar population due its high litter size, it has been regarded as a serious pest of agriculture crops in Pakistan. Large-scale cultivation of sugarcane crop has led to corresponding increase in damage to sugarcane and other crops cultivated in the distribution range of this species. The increase in population of the wild boar in urban areas is very high and also on the increase day by day due to a number of factors. The most important of these factors are appealing habitat conditions, escape cover and the availability of the relished food present at dumping places besides the hotels and food points near the university hostels [5]. The major crop of district Chakwal is ground nut. The wild boar seriously damages the nut crop in the district. [6]. Different control strategies were adopted in various parts of the world for controlling its population. These include trapping, electric fencing, netting and different kinds of baits [7].

In Pakistan, the most common mechanical methods adopted for the control of wild boar include permanent fencing, panel traps, loop traps, snare traps, box traps, and chemical baiting, shooting, and hunting with dogs [8]. Recent damage assessments of losses in sugarcane due to wild boars indicate it is a significant agricultural and economic pest [9]. In Pakistan, there are very few control measures available for farmers to use and these measures are utilized are practiced inefficiently. Keeping in view the damages caused by wild boars to crops as well as livestock, the present study was conducted with the main aim to control this wild animal and to avoid crop damage by designing efficient management strategy. Wild boars contribute to more than $60 \%$ of the total losses per crop. Many farm areas located near the forests or wood lands had given up agriculture due to increased damages by wild boars [10].

As the chemical control cause environmental and social problems this was main reason to use trapping technique to control the population of wild boar. Trapping is safe technique to control the population as Islamabad is the capital of Islamic republic of Pakistan. Wild boar causing damage in different ways like destruction in landscape, hitting vehicles and create disturbance in residential areas of the city Islamabad.

\section{Materials and methods}

The current study was executed the Islamabad, capital of Pakistan. The interviews were conducted with local residents of the area and field employees of the Capital Development Authority (C.D.A.) identify problematic sites, Seven study sites were selected including. C.D.A-Nursery (Lat N33 40 45.3, Long E73 08 19.1), F-9 Park (Lat N33 42 34.3, Long E73 01 20.8), Faisal Mosque (Lat N33 43 41.3, Long E73 02 29.4), Jasmine Garden (Lat N33 42 04.5, Long E73 05 12.5), Prime Minister House (Lat N33 44 44.0, Long E73 05 27.0), Quaid-e-Azam University (Lat N33 44 46.2, Long E73 08 24.8) and Rawal Lake (Lat N33 42 5.9, Long E73 07 42.5).. Three different types of traps, Panel Trap, Doublespike Snare Trap (DST) and Loop trap (LT) were used at all of the seven selected sites. The traps were fixed at regular intervals and the total captured animals were counted. At each study site 15 traps of each type were used to catch the wild boar; captured boars were counted on daily basis during trapping operation at the study sites to assess the trapping efficacy. The date was collected and analyzed with LSD test [11]. 


\section{Results and discussion}

Three types of traps viz. Double-spike Snare Trap (DST), Loop Trap (LP) and Panel Trap (PT) were used in this study to test their effectiveness in controlling wild boar population. DST and LT trap types were installed at suitable places in damp depressions wherever there was maximum number of fresh wild boar tracks indicating their use of these sites as routes during their nocturnal foraging visits whereas the PT were operated on relatively plane patches of ground at trash dumping sites, regularly visited by the wild boar herds in search of food.

Number of Trapped Boars, Sows and Piglets During two years of trapping study, a total of 529 wild boars were trapped from seven different study sites located in the city of Islamabad, Table 1. Out of these, 277 were trapped during the first year and 252 in the year 2. Amongst the trapped wild boar, 201 were male (108 in year 1 and 93 in year 2), 212 were females (114 in year 1 and 98 in year 2) and 116 were piglets (55 in year 1 and 61 in year 2), out of 201 captured males, $28,37,23,21,31,26$ and 35 respectively were trapped at C.D.A-Nursery, F-9 Park, near Faisal Mosque, Jasmine Garden, in the vicinity of Prime Minister House, around residential hostels of Quaid-e-Azam
University and near Rawal Lake and out of 212 captured females, 33, 28, 35, 34, 25, 27 and 30 and amongst 116 piglets, 16, 16, 26, 16, 19, 12 and 11 were captured/trapped respectively from the study sites.

The trapping was most successful near Faisal Mosque with a total catch of 84 animals (46 in year 1 and 35 in year 2) followed by a catch of 81 at F-9 Park (36 in year 1 and 45 in year 1), 77 at C.D.ANursery (42 in year 1one and 35 in the year 2), 76 near Rawal Lake (39 in the year 1 and 37 in the year 2), 75 in the vicinity of Prime Minister's House (34 in the year 1 and 41 in the year 2), 71 at Jasmine Garden (42 in the year 1 and 29 in the year 2), and it was least successful in peripheral area of residential hostels of the Quaid-e-Azam University with a catch of 65 animals, 38 caught during the first and 27 during the year 2 of this study, as shown in (Table 1).

Growing concerns surrounding established and expanding populations of wild pigs (Sus scrofa) have created the need for rapid and accurate surveys of these populations. Maximization of time-lapse interval should decrease data and processing loads, and use of simple, available bait should decrease cost and effort associated with more complicated baits [12].

Table 1 Number of wild boar males, females and piglets captured at seven sites of Islamabad in two-year study

\begin{tabular}{|c|c|c|c|c|c|c|c|c|c|c|c|c|}
\hline \multirow[t]{2}{*}{ Site } & \multicolumn{3}{|c|}{ Year 1} & \multirow{2}{*}{$\begin{array}{c}\text { Total } \\
\text { Y-1 } \\
\end{array}$} & \multicolumn{3}{|c|}{ Year 2} & \multirow{2}{*}{$\begin{array}{c}\text { Total } \\
\text { Y-2 }\end{array}$} & \multicolumn{3}{|c|}{ Total } & \multirow{2}{*}{$\begin{array}{c}\text { Grand } \\
\text { Total }\end{array}$} \\
\hline & Male & Female & Piglet & & Male & Female & \begin{tabular}{|l|} 
Piglet \\
\end{tabular} & & Male & Female & piglet & \\
\hline C.D.A-N & 16 & 17 & 9 & 42 & 12 & 16 & 7 & 35 & 28 & 33 & 16 & 77 \\
\hline F-9P & 16 & 12 & 8 & 36 & 21 & 16 & 8 & 45 & 37 & 28 & 16 & 81 \\
\hline FM & 13 & 22 & 11 & 46 & 10 & 13 & 15 & 38 & 23 & 35 & 26 & 84 \\
\hline JG & 13 & 18 & 11 & 42 & 8 & 16 & 5 & 29 & 21 & 34 & 16 & 71 \\
\hline $\mathrm{PMH}$ & 14 & 15 & 5 & 34 & 17 & 10 & 14 & 41 & 31 & 25 & 19 & 75 \\
\hline QAU & 17 & 14 & 7 & 38 & 9 & 13 & 5 & 27 & 26 & 27 & 12 & 65 \\
\hline RL & 19 & 16 & 4 & 39 & 16 & 14 & 7 & 37 & 35 & 30 & 11 & 76 \\
\hline Total & 108 & 114 & 55 & 277 & 93 & 98 & 61 & 252 & 201 & 212 & 116 & 529 \\
\hline
\end{tabular}

C.D.A-N = Capital Development Authority's Nursery, F-9P = Public Park in F/9 Sector, FM = Vicinity of Faisal Mosque, RJG = Rose and Jasmine Garden, PMH = Vicinity of Prime Minister House, QAU = Vicinity of the Hostels of Quaid-e-Azam University and RL = Vicinity of Rawal Lake 
Trap-types and capture of wild boars

The site and trap-type-wise capture of wild boars during year 1 and year 2 of this study is given in Table 2, Out of 529 animals trapped, 55, 53 and 169 (total 277) were trapped respectively in Double-spike Snare Traps, Loop Traps and Panel Traps during Year 1, and 52, 58 and 142 (Total 252) during year 2 of this study. A comparison of the animals trapped in different trap types given in Table 1.

The number of wild boars captured in Panel Traps differed significantly from that captured either in Double-Spike Snare Traps or in Loop Traps. However, the number of wild boars captured in Double-spike Snare Traps and that captured in Loop Traps did not differ statistically from each other (Table-3). Results of the current study were in the line of $[13,14]$.

Table 2. Number of wild boars trapped in three different types of traps

\begin{tabular}{|c|c|c|c|c|c|c|c|c|c|}
\hline \multirow{2}{*}{ Site } & \multicolumn{2}{|c|}{ Year 1 Trapping } & \multirow{2}{*}{ Total } & \multicolumn{2}{c|}{ Year 2 Trapping } & \multicolumn{2}{c|}{ Total } & Grand \\
& DST & LT & PT & Year 1 & DST & LT & PT & Year 2 & Total \\
\hline C.D.A-N & 8 & 7 & 27 & 42 & 7 & 6 & 22 & 35 & 77 \\
\hline F-9P & 6 & 3 & 27 & 36 & 8 & 11 & 26 & 45 & 81 \\
\hline FM & 8 & 12 & 26 & 46 & 8 & 6 & 24 & 38 & 84 \\
\hline RJG & 10 & 7 & 25 & 42 & 7 & 10 & 12 & 29 & 71 \\
\hline PMH & 8 & 8 & 18 & 34 & 7 & 9 & 25 & 41 & 75 \\
\hline QAU & 7 & 8 & 23 & 38 & 7 & 7 & 13 & 27 & 65 \\
\hline RL & 8 & 8 & 23 & 39 & 8 & 9 & 20 & 37 & 76 \\
\hline Total & $\mathbf{5 5}$ & $\mathbf{5 3}$ & $\mathbf{1 6 9}$ & $\mathbf{2 7 7}$ & $\mathbf{5 2}$ & $\mathbf{5 8}$ & $\mathbf{1 4 2}$ & $\mathbf{2 5 2}$ & $\mathbf{5 2 9}$ \\
\hline
\end{tabular}

Double-spike Snare Trap (DST), Loop Trap (LT) and Panel Trap (PT)

\section{Relative efficiency of the trap-types}

The data on capture of wild boar by different trap type has been summarized Table 3, properties of capture worked out in Table 3 and relative efficiency compared in Table 3 with respect to minimum number of captures by any trap type with respect to the number of successful captures, the PT proved to be the most efficient trap at all the trapping sites during year 1 expect for at FM were it was equal in capture with a capture of 12 wild boars Table 3. It was $266 \%, 114 \%, 86$ $\%, 58 \%$, and $25 \%$ more efficient than the LT at the F-9P, C.D.A-N, JG and PMH respectively, and it remained 50\% and $14 \%$ more efficient than the DST at FM and QAU respectively. Overall, it was $58 \%$ more efficient than LT in the combined data for all the sites for year 1 Table 4. Once populations are established, wild boar has proven to be extremely difficult to control, and close to impossible to eradicate. If effective control and removal techniques are to be developed, we must determine if wild boar populations respond to reductions in density by increasing reproductive output [15].

Table 3. Proportion (\% age) of successful captures for the three trap types. Three traps of each type were operated on each site for fifteen days (i.e. $3 \times 15=45$ trap-nights per trap type per study site) during year 1 and year 2 of this study

\begin{tabular}{|c|c|c|c|c|c|c|c|c|}
\hline \multirow{2}{*}{ Site } & \multicolumn{3}{|c|}{ Year 1 } & All Traps & \multicolumn{3}{|c|}{ Y2 } & All Traps \\
\cline { 2 - 6 } & DST & LT & PT & Year 1 & DST & LT & PT & Year 2 \\
\hline C.D.A-N & 17.78 & 15.56 & 33.33 & 5.93 & 15.56 & 13.33 & 24.44 & 5.19 \\
\hline F-9P & 13.33 & 6.67 & 24.44 & 4.44 & 17.78 & 24.44 & 26.67 & 5.93 \\
\hline FM & 17.78 & 26.67 & 26.67 & 5.93 & 17.78 & 13.33 & 22.22 & 5.93 \\
\hline
\end{tabular}




\begin{tabular}{|c|c|c|c|c|c|c|c|c|}
\hline JG & 22.22 & 15.56 & 28.89 & 7.41 & 15.56 & 22.22 & 17.78 & 5.19 \\
\hline PMH & 17.78 & 17.78 & 22.22 & 5.93 & 15.56 & 20.00 & 24.44 & 5.19 \\
\hline QAU & 15.56 & 17.78 & 26.67 & 5.19 & 15.56 & 15.56 & 13.33 & 5.19 \\
\hline RL & 17.78 & 17.78 & 24.44 & 5.93 & 17.78 & 20.00 & 22.22 & 5.93 \\
\hline All Sites & 17.46 & 16.83 & 26.67 & 20.32 & 16.51 & 18.41 & 21.59 & 18.84 \\
\hline
\end{tabular}

Table 4. A comparison of the relative efficiency of the three types of traps in comparison to the least successful trap type in terms of the number of successful captures. Three traps of each type were operated on each site for fifteen days (i.e. $3 \times 15=45$ trap-nights per trap type per study site) during year 1 and year 2 of this study

\begin{tabular}{|c|c|c|c|c|c|c|c|c|}
\hline \multirow{2}{*}{ Site } & \multicolumn{3}{|c|}{ Year 1 } & All Traps & \multicolumn{3}{|c|}{ Y2 } & All Traps \\
\cline { 7 - 9 } & DST & LT & PT & Year 1 & DST & LT & PT & Year 2 \\
\hline C.D.A-N & $+14 \%$ & - & $+114 \%$ & $+34 \%$ & $+17 \%$ & - & $+83 \%$ & - \\
\hline F-9P & $+100 \%$ & - & $+266 \%$ & - & - & $+37 \%$ & $+50 \%$ & $+14 \%$ \\
\hline FM & - & $50 \%$ & $+50 \%$ & $+34 \%$ & $+33 \%$ & - & $+67 \%$ & $+14 \%$ \\
\hline JG & $+43 \%$ & - & $+86 \%$ & $+67 \%$ & - & $+43 \%$ & $+14 \%$ & - \\
\hline PMH & - & - & $+25 \%$ & $+34 \%$ & - & $+29 \%$ & $+57 \%$ & - \\
\hline QAU & - & $14 \%$ & $+71 \%$ & $+17 \%$ & $+17 \%$ & $+17 \%$ & - & - \\
\hline RL & $+4 \%$ & - & $+58 \%$ & $+34 \%$ & - & $+12 \%$ & $+25 \%$ & $+14 \%$ \\
\hline All Sites & $+4 \%$ & - & $+58 \%$ & - & - & $+12 \%$ & $+31 \%$ & - \\
\hline
\end{tabular}

\section{Authors' contributions}

Conceived and designed the experiments: I Ashraf, Performed the experiment: $\mathrm{SAH}$ Bukhari \& A Maqsood, Analyzed the data: I Ashraf \& A Maqsood, Contributed reagents / materials/ analysis tools: I Ashraf \& Ishtiaq Ahmad, Wrote the paper: Ishtiaq Ahmad.

\section{Acknowledgement}

We are thankful to Higher Education Commission, (HEC) Islamabad for financial support for the project.

\section{References}

1. Beg MA (1990). General Principals of vertebrate pest management. A training manual on vertebrate pest management. NARC/PARC, Islamabad.

2. Khan MH (1990). Non-Chemical methods of wild boar control. Training Manual of Vertebrate Pest Management. NARC, Islamabad. 157-160.

3. Roberts TJ (1997). Mammals of Pakistan. Revised edition. Ernest Benn Ltd., London, 526.

4. Brooks JE, Ahmad E \& Hussain I (1988).
Characteristics of damage by vertebrate pests to groundnut in Pakistan. Vert. Pest Conf. 1-3 March, 1988, Monterey, California, 129-33.

5. Khan RA (1983). Biology, habitat patterns and control of wild boar in the area of district Faisalabad. (M.Sc. Thesis, Department of Forestry, AUF)

6. Abbas M, Hafeez S, Ahmad RK \& Shahbaz M (2004). Efficacy of different methods to control wild boars: a perception of farmers of the Faisalabad Division. Pak J Agri Sci 41: 144-145.

7. Haider E (2007). Wild boar a menace to groundnut crop. Dawn Article January 29, Pakistan

8. Sweitzer RA \& Gonzales BJ (1997). "A Modified Panel Trap and Immobilization Technique for Capturing Multiple Wild Pig." Wildlife Society Bulletin 25: 699705.

9. Brooks JE, Ahmad E, Hussain I \& Khan MH (1989). The agricultural importance of the wild boar (Sus scrofa L) in 
Pakistan. Tropical Pest Mangt 35: 278281.

10. Ucarli Y (2011). Effects of wild boar (Sus scrofa L.) on farming activities: A case study of Turkey. African Journal of Biotechnology 10: 8823-8828.

11. Hafeez S, Khan ZH, Khan RA, Qadir I \& Rashid F (2007). Comparative efficacy of some trap for controlling Porcupines, wild boars and other vertebrate pests. Pak J Agri Sci 44: 150153.

12. Shafi MH \& Khokhar AR (1986). Some observations on wild boar (Sus scrofa) and Its control in sugarcane area of the Punjab, Pakistan. J Bombay Nat Hist
Soc 83: 63-67.

13. Ashraf I, Khan RA, Yaqoob S \& Ali A (2013). Eco-biological study of wild boar (Sus scrofa cristatus) in Islamabad area, Pakistan. J Agric Res 51: 307-315.

14. Smith TN, Smith MD, Johnson DK \& Ditchkoff SS (2014). Evaluation of continuous-catch doors for trapping wild pigs. Wildlife Society Bulletin 38: 175-181.

15. Ditchkoff, SS, Jolley DB, Sparklin BD, Hanson LB, Mitchell MS \& Grand JB (2012). Reproduction in a population of Wild Pigs (Sus scrofa) subjected to lethal control. Journal of Wildlife Management 76: 1235-1240. 